\title{
Política de Educação de Jovens e Adultos (EJA) do estado da Bahia (Brasil): caminhos para a construção curricular ${ }^{1}$
}

\author{
Magna Simone de Souza Pinheiro ${ }^{2}$ \\ Edinaldo Medeiros Carmo ${ }^{3}$ \\ Maria Cristina Dantas Pina ${ }^{4}$
}

\section{Resumo}

Este artigo é fruto de uma investigação que teve como objetivo traçar o cenário de elaboração da Política de Educação de Jovens e Adultos (EJA) do estado da Bahia, no sentido de compreender as perspectivas desse documento implantado nas escolas em 2009. Trata-se de uma pesquisa qualitativa, na qual se utilizou a análise documental. Os resultados mostram que a elaboração contou com participação de diversos autores, porém, alguns mais influentes. A diferença na faixa etária dos alunos foi um dos problemas apontados. Considera-se que a EJA deve ser compreendida como uma modalidade de formação humana contínua e emancipadora, exigindo do professor conhecimentos epistemológicos para consolidar uma percepção de como os jovens e adultos constroem seus espaços de atuação na sociedade.

Palavras-chave: Currículo; Educação de Jovens e Adultos; Política de EJA.

\section{Literacy environment in preschool from a world reading perspective: teachers in dialogue}

\begin{abstract}
This article is the product of a research aimed to outline the landscape for the elaboration of the Youth and Adult Education Policy (YAE) in the state of Bahia, in order to understand the perspective of this document, implemented in schools in 2009. This is a qualitative research, using document analysis. The results show that the elaboration had the participation of several authors, however, some of them were more influential. The difference in the age range of the students was one of the problems mentioned. It is considered that YAE should be understood as a modality of continuing and emancipatory human formation, demanding epistemological knowledge from the teacher, in order to consolidate a perception of how young people and adults carve out their spaces of action in society. Keywords: Curriculum; Youth and Adult Education; EJA policy.
\end{abstract}

\section{Introdução}

As políticas educacionais desenvolvidas no Brasil vêm sendo inseridas em um contexto de desvalorização, principalmente, quando diz respeito à Educação de Jovens e Adultos. Compreendemos que a educação, em conformidade com as legislações e as mudanças dos grupos que chegam ao poder, sempre esteve marcada por avanços e retrocessos, como também

\footnotetext{
${ }^{1}$ Este artigo é parte de uma investigação em nível de mestrado.

${ }^{2}$ Secretaria Estadual de Educação do Estado da Bahia, Vitória da Conquista, Bahia, vmonesp@yahoo.com.br

${ }^{3}$ Universidade Estadual do Sudoeste da Bahia (UESB), Vitória da Conquista, Bahia, medeirosed@uesb.edu.br

${ }^{4}$ Universidade Estadual do Sudoeste da Bahia (UESB), Vitória da Conquista, Bahia, mcristina.pina@gmail.com
} 
as políticas educacionais são reiteradamente fragmentadas, o que mostra a ausência de compromisso do poder público com as demandas sociais.

Dado o exposto, toda política educacional é construída por meio de influências, sejam elas internacionais, nacionais ou locais; dentre estes, os organismos internacionais fazem pressões na sua elaboração. Além disso, temos as lutas em âmbito nacional, tendo em vista os seus próprios interesses e as influências locais, ou seja, para onde e para qual público destina-se a política. É importante ressaltar que as influências dos organismos internacionais asseguram muitas situações relativas à educação, não só no Brasil, mas no mundo, sob o viés de prestar auxílio aos países em desenvolvimento. Assim, no que se refere aos organismos internacionais, Libâneo (2016, p.43) afirma que "[...] as finalidades dessas instituições multilaterais sempre estiveram ligadas à cooperação técnica e financeira a países com dificuldades, por meio de empréstimos para realização de programas relacionados à saúde, educação, saneamento etc.". Uma dessas instituições é o Banco Mundial, principal representante do ideário neoliberal, que padroniza as iniciativas educacionais, assegurando trazer o estado mínimo e ampliar para a perspectiva do mundo privado todas as iniciativas.

Esse aspecto apontado por Libâneo (2016) chama a atenção pelo fato de as agências internacionais assumirem um posto de destaque nas formulações dos currículos. Assim, é dada à escola a responsabilidade de solucionar os problemas sociais, o que remete à lógica da responsabilização. Como a escola pode dar conta de tantas mazelas sociais, senão por meio do acolhimento do aluno, abraçando os seus saberes e particularidades? No entanto, como a concepção de educação das agências é voltada para um currículo com foco nos resultados, correse o risco de causar sérios prejuízos ao educando, pois essas políticas, no contexto escolar, contribuem para que os resultados sejam mascarados, fornecendo para a disputa entre os próprios professores e as escolas de modo geral.

Lopes e Macedo (2011a, p.239) argumentam que “[...] as perspectivas neoliberais sustentam discursos em torno da necessidade de novas e eficientes formas de gerenciamento das escolas, políticas de responsabilização de professores pelos resultados dos alunos e introdução nas escolas de disposições e interesses de mercado". Na visão neoliberal, existe uma inclinação da escola em desenvolver um currículo conforme as imposições do mercado, obrigando a demonstrar resultados mediante as avaliações externas. Entretanto, acreditamos 
que a política não tem um movimento apenas de cima para baixo, embora isso possa acontecer, também há um movimento contrário, de baixo para cima. Quando falamos da constituição da política educacional temos essas tensões e conflitos o tempo inteiro, uma vez que esse documento está em constante transformação.

Conforme Mainardes (2006), no processo de construção das políticas educacionais, além da participação de vários membros da sociedade, há também, mesmo que de forma parcial, a participação dos profissionais que desempenham uma função na escola. Porém, é relevante saber qual é a dimensão do envolvimento desses profissionais com as políticas que são efetivadas nas escolas, pois sabemos que os textos políticos são resultados das normas e regras que devem direcionar a escola e são interpretados de formas diversas conforme o contexto em que estão inseridos.

Neste estudo buscamos traçar o cenário de elaboração da Política de Educação de Jovens e Adultos (EJA) do estado da Bahia (Brasil) numa abordagem crítica, no sentido de compreender as perspectivas desse documento implantado nas escolas em 2009. Tomando como referência este documento, a pesquisa é de cunho qualitativo, considerando os significados, os valores e as relações (MINAYO, 2014). Adotamos a análise documental, a qual representa uma estratégia importante na pesquisa qualitativa ao acrescentar conhecimento adquirido por outras estratégias, de forma a expor aspectos novos de um tema. A análise documental nasce com a apreciação prévia de um documento e, consequentemente, a sua crítica conforme o contexto, credibilidade, autores e outros aspectos que o pesquisador julgar necessários.

Para Bardin (2016, p.51) a análise documental é "[...] uma operação ou um conjunto de operações visando representar o conteúdo de um documento, sob a forma diferente do original, a fim de facilitar num estado ulterior a sua consulta e referenciação". A finalidade da análise documental é lidar com os documentos abordados numa pesquisa, utilizando uma configuração mais concreta e condensada, tendo em vista o máximo de elementos importantes para viabilizar a sua consulta. Assim, mediante tratamento analítico do documento, elegemos algumas temáticas de análise, a saber: Proposta curricular de EJA do estado da Bahia (Brasil) - primeiras aproximações; Jovens e Adultos: oportunidade de acesso à educação; Abrangência da Educação de Jovens e Adultos e, para finalizar a análise do documento, destacamos ainda as Orientações metodológicas e organização do currículo para a EJA. 


\section{Proposta curricular da Educação de Jovens e Adultos (EJA) do estado da Bahia (Brasil) - primeiras aproximações}

O documento intitulado Política de EJA da Rede Estadual é um documento condensado, constituído por apenas 36 páginas, e está dividido em sete seções, mais as referências e os apêndices. Com o objetivo de orientar o trabalho dos professores para que estes promovam metodologias que visem o desenvolvimento pleno do educando, o documento traz a proposta curricular implantada nas escolas estaduais no ano de 2009. Partindo desse pressuposto, o texto da política da EJA está fundamentado na pedagogia crítica com referências aos estudos de Paulo Freire, assim como, uma breve referência às teorias da psicogênese de Piaget.

Em um primeiro momento, apresenta uma concepção de educação para a construção do novo currículo dessa modalidade de ensino. Em seguida, o documento apresenta aspectos sobre a metodologia, ressaltando que esta deve estar em consonância com a realidade dos sujeitos da EJA.

O texto traz uma estrutura curricular organizada em eixos temáticos que devem ser desenvolvidos durante um ano, apontando os desafios a serem enfrentados pela EJA e o perfil do professor formador para trabalhar com essa modalidade de ensino. No início do documento, há referência ao fato de que a construção da política envolveu a participação de vários representantes da sociedade, com a finalidade de atender as demandas e expectativas da realidade da EJA. O documento evidencia:

O material aqui apresentado é fruto da escuta dos principais sujeitos da EJA: educandos(as), educadores, gestores e coordenadores pedagógicos das Diretorias Regionais de Educação - DIREC, bem como representantes dos diversos segmentos que dão forma ao Fórum Estadual de EJA, quais sejam: Universidades (Universidade do Estado da Bahia - UNEB e Universidade Federal da Bahia - UFBA), Movimentos Sociais (Movimento de Educação de Base MOVA), Sistema S (Serviço Social da Indústria - SESI), Organização NãoGovernamental (Centro de Estudos e Assessoria Pedagógica - CEAP), Gestão Pública (Secretaria de Educação do Estado - SEC/BA e Secretaria Municipal de Educação e Cultura - SMEC/SSA) Fóruns Regionais de EJA (BAHIA, 2009, p.9).

Podemos constatar que, no processo de elaboração da política de EJA, ocorreu a influência e a participação de diversos segmentos e atores. Entretanto, vale considerar que, 
conforme destaca Ball (1994) apud Lopes e Macedo (2011b, p.258), a participação desses segmentos na elaboração da política curricular "[...] não significa [...] que todas as vozes são ouvidas na polifonia do texto curricular, na medida que há posições legitimadas e outras não. No interior do que poderia ser chamado de posições legitimadas, ainda há uma pluralidade de grupos em disputa". Segundo Ball (1994), na produção da política, além das vozes legitimadas, há também no centro desses grupos outras vozes em disputa que almejam deixar suas marcas nesses textos.

A Resolução do Conselho Nacional de Educação (CNE) e da Câmera de Educação Básica (CEB), ao instaurar as Diretrizes Operacionais para a Educação de Jovens e Adultos, no Art. 2으, atribui:

Para o melhor desenvolvimento da EJA, cabe a institucionalização de um sistema educacional público de Educação Básica de jovens e adultos, como política pública de Estado e não apenas de governo, assumindo a gestão democrática, contemplando a diversidade de sujeitos aprendizes, proporcionando a conjugação de políticas públicas setoriais e fortalecendo sua vocação como instrumento para a educação ao longo da vida (BRASIL, 2010, p.1).

Em consonância com a resolução, os autores da política procuraram desenvolver espaços de diálogos que se concretizavam em reuniões, fóruns EJA, seminários e por meio de questionários respondidos pelos professores de diversas partes da Bahia. Vale considerar que, mesmo que a intenção tenha sido atingir várias regiões do estado, sabemos que essa estratégia não contempla todas escolas, muito menos, docentes e alunos. Frisamos que os movimentos preparatórios para as Conferências Internacionais de Educação de Adultos (Confintea) foram muito importantes para a escolha dos princípios que norteiam a política de EJA. Foi realizada no Brasil no ano de 2009 a VI Confintea ${ }^{5}$, a qual sensibilizou os diversos setores envolvidos com a EJA para compor uma comissão nacional organizadora do encontro preparatório para a

\footnotetext{
${ }^{5}$ A VI Conferência Internacional de Educação de Adultos (Confintea) foi realizada em Belém, em dezembro de 2009. Gadotti (2009, p.28), por ocasião da conferência, afirmou que “[...] o documento final [...] deverá conter um marco de ação para impulsionar a Educação de Adultos no mundo, buscando sinergias com outras agendas, como a Década da Educação para o Desenvolvimento Sustentável, a Década da Alfabetização, o programa Educação para Todos e a Declaração sobre os objetivos do Desenvolvimento do Milênio. Esperamos que ele deixe mais claras as políticas públicas de financiamento da Educação de Adultos e que contemple também a educação popular como paradigma da Educação de Adultos, como grande contribuição da América Latina ao pensamento pedagógico universal”.
}

Periódico Horizontes - USF - Itatiba, SP - Brasil - e020041 
conferência seguinte (GADOTTI, 2009).

O resultado da sensibilização culminou na formação de fóruns e reuniões com os vários segmentos da comunidade, como também a participação de educadores e educandos. De acordo com esse cenário, os "Documentos originados dessas conferências assinadas pelos paísesmembros, as orientações políticas e técnicas do Banco Mundial vêm servindo de referência às políticas educacionais do Brasil” (LIBÂNEO, 2016, p.42). No entanto, Libâneo adverte que

[...] as políticas educacionais formuladas por organismos internacionais desde 1990 presidem as políticas para a escola em nosso país, havendo razões para suspeitar que elas vêm afetando negativamente o funcionamento interno das escolas e o trabalho pedagógico-didático dos professores (LIBÂNEO, 2016, p.47).

Dessa maneira, a educação concentrou-se em atender as demandas relacionadas às questões de âmbito social e econômico conforme as exigências do contexto do mundo globalizado. Ainda, vale ressaltar que, segundo Ball (1994), os textos políticos são resultados de lutas, negociações e acordos entre grupos que exercem o poder na sociedade, como visualizado durante a década de 1990 em vários momentos de tensões e contestações a essa política por parte da sociedade brasileira, particularmente os setores organizados em sindicatos e associações.

Cabe considerar que a EJA é destinada a todas as pessoas que, por razões diversas, não puderam dar continuidade aos estudos na idade regular, pois, fatores econômicos e sociais excluem esses indivíduos da escola durante a infância e adolescência. Nesse caso, as políticas de educação disseminadas no Brasil, principalmente para a EJA, preconizam a escola como lugar no qual os alunos possam conseguir sair da condição precária em que vivem e que tenham em sua estrutura curricular estratégias de redução de pobreza, mas sobretudo, inserção no mercado de trabalho (LIBÂNEO, 2016).

\section{Jovens e adultos: oportunidade de acesso à educação}

A consciência do direito à educação cresce entre jovens e adultos que não conseguiram continuar seus estudos no ensino regular. Nesse caso, o texto da Política da EJA do estado da 
Bahia ressalta a necessidade de garantir a Educação Básica de jovens e adultos, enquanto direito. Para isso, a Política estabelece que a EJA deve estar compreendida como um processo contínuo de formação humana.

Quanto à implementação das políticas de educação no Brasil, Saviani (2014) destaca que há uma notória descontinuidade, e, em consequência disso, o Brasil ainda não conseguiu diminuir as taxas de analfabetismo. Como se pode ver, as tendências da política educacional brasileira são marcadas por avanços e retrocessos, na medida em que os seus elaboradores buscam imprimir as influências que possuem, nas quais, quase sempre, prevalecem os interesses privados mascarados de interesse público. Considerando esses aspectos, Lopes e Macedo (2011a, p.241) dispõem que "Decisões coletivas sobre a educação, antes garantidas pelo Estado, são tornadas individuais, reguladas por mecanismos privados e corporativos de mercado", ou seja, os interesses do mercado sobre a educação revelam um contexto de interesse na formação de mão-de-obra com baixo custo como resposta à crise do capitalismo.

Nos dias atuais muito se tem discutido sobre o fato de que a educação deve ser reafirmada como direito do cidadão e dever do Estado, da sociedade e da família. Nesse sentido, o documento analisado aproxima-se desse discurso ao abordar que o currículo para a EJA deve estar ancorado em uma pedagogia crítica, isto é, a educação deve conduzir o desenvolvimento dos cidadãos para que sejam capazes de analisar e transformar sua realidade social, cultural e histórica. Para Freire (2003), a prática educativa a ser desenvolvida com a EJA deve promover a leitura crítica do mundo e os educandos devem ser considerados como sujeitos autônomos. Do mesmo modo, o educador crítico deve considerar a voz dos alunos e suas concepções de mundo para que esses se sintam agentes transformadores e atuantes no processo.

Conforme o documento, o compromisso do Estado é democratizar e efetivar o processo educacional à luz de "[...] um novo fazer coletivo, o qual se instituirá a partir do diálogo com os próprios jovens e adultos, e com os educadores e educadoras da EJA" (BAHIA, 2009, p.11). Somam-se a isso alguns questionamentos relacionados à EJA quanto aos sujeitos que a constituem. $\mathrm{O}$ documento destaca:

[...] contribuir com a democratização e efetividade do processo educacional construído pela Educação de Jovens e Adultos do nosso Estado. Afinal, quem são os seus sujeitos? A que e a quem a EJA se destina? Que significado esta 
modalidade assume em uma sociedade que se pretende globalizada e pósmoderna? E ainda, quais as verdadeiras possibilidades educacionais que são oferecidas aos educandos jovens e adultos na sociedade da informação? (BAHIA, 2009, p.11).

Nesse prisma, o texto traz uma visão dos sujeitos dessa modalidade de ensino como homens e mulheres que lutam pela sobrevivência nas cidades ou campos, donas de casa, operários e assalariados. Há uma necessidade de discussão do currículo mais aprofundada, a fim de melhor conhecer quem é esse aluno e em que ele se diferencia em cada localidade e região. Assim, a política de EJA reconhece que "São sujeitos de direito da EJA jovens, adultos e idosos; homens e mulheres que lutam pela sobrevivência nas cidades ou nos campos. Em sua maior parte, os sujeitos da EJA são negros e, em especial, mulheres negras" (BAHIA, 2009. p.11).

O documento considera ainda que o público dessa modalidade é caracterizado por pessoas que, por diversos fatores, não conseguiram acompanhar o ensino fundamental. No entanto, esse público, segundo o documento, vem diminuindo ao longo do tempo, e, em contrapartida, a presença de adolescentes que saíram da educação fundamental vem aumentando no ensino noturno. Vale ressaltar que é imprescindível saber quem é o público da EJA, no sentido de elaborar currículos mais atraentes e específicos para tal modalidade. Para Libâneo (2016, p.46), essas colocações transitam pela imposição de "Criar os insumos necessários para que o aluno alcance a aprendizagem como produto, ou seja, conhecimento e habilidades necessárias ao mercado de trabalho". Considerando ainda as particularidades presentes na modalidade EJA, o documento (BAHIA, 2009) menciona que,

No cenário educacional, configuram-se enquanto aqueles que não tiveram passagens anteriores pela escola ou, ainda, aqueles que não conseguiram acompanhar e/ou concluir a Educação Fundamental, evadindo da escola pela necessidade do trabalho ou por histórias margeadas pela exclusão por raça/etnia, gênero, questões geracionais, de opressão entre outras (BAHIA, 2009. p.12).

Dessa maneira, reconhecer a diversidade e a identidade do público que faz parte da EJA significa criar possibilidades para que esse ultrapasse as barreiras que lhe são impostas, tal como desenvolver estratégias de ensino que contribuam para a compreensão do conhecimento científico, sem desconsiderar o senso comum. Ainda é possível destacar que o documento 
apresenta argumentos que consideram assegurar a prática pedagógica condizente com a realidade, mas, para que essa prática pedagógica seja de fato concretizada, é preciso enfrentar alguns desafios que são impostos, como exemplos, dificuldade de acesso à escola, fracasso e evasão escolar.

O documento também ressalta que é preciso estabelecer diálogos com as coordenações de inclusão e diversidade, com o objetivo de buscar colaboração para projetos que atendam a EJA e a indígenas que necessitem de ações educativas especiais. Orienta, ainda, que os órgãos responsáveis pela Educação de Jovens e Adultos construam relações harmoniosas, a fim de alcançar as etapas necessárias para garantir o acesso dos sujeitos à educação.

\section{Abrangência da Educação de Jovens e Adultos}

A Educação de Jovens e Adultos é uma modalidade de ensino que atende jovens e adultos trabalhadores. O documento estabelece que os jovens sejam matriculados a partir dos 18 anos, idade mínima para o acesso ao ensino noturno, conforme institui o Conselho Nacional de Educação (CNE). A despeito disso, a política afirma que "A revisão do Parecer da EJA, promovida pelo Conselho Nacional de Educação (CNE), a qual resultou no Projeto de Resolução, indica a elevação da idade para acesso na EJA, assim como a ampliação da educação fundamental e média no noturno [...]" (BAHIA, 2009, p.13). No documento é citado também o art. 2을 do Estatuto da Criança e do Adolescente (ECA), o qual estabelece, com relação à idade, os conceitos de criança e adolescente. Conforme o Estatuto, considera-se criança aquela que possui doze anos incompletos, e adolescentes, pessoas com idade entre doze e dezoito anos (BRASIL, 1990).

De acordo com o documento, além da EJA, os programas do Governo Federal, como o Programa Nacional de Inclusão de Jovens, Educação, Qualificação e Participação Cidadã (PROJOVEM) - e, no campo, o Programa Nacional de Integração da Educação Profissional com a Educação Básica na Modalidade de Educação de Jovens e Adultos (PROEJA) -, também definem a idade mínima de dezoito anos para a participação nessas plataformas. Ainda com relação à idade, o texto alude aspectos referentes aos educadores e educandos ao mencionar a presença de alunos adolescentes menores de dezoito anos nas turmas da EJA, destacando: 
[...] a permanência de alunos adolescentes (de 14 a 17 anos) na EJA tem trazido grandes prejuízos à prática dos educadores, que se sentem perdidos frente às expectativas, saberes e ritmos tão variados. Além disso, é preciso atentar para o fato de que não há metodologia nem material didático que possa dar conta de tamanha diversidade. Consequentemente, compromete-se a aprendizagem dos educandos, os quais atribuem valências diferentes à escola e ao processo de formação (BAHIA, 2009, p.10).

É importante salientar que, além das dificuldades registradas pelos educadores em torno desse problema, alguns profissionais da EJA possuem um olhar negativo sobre os educandos, o que contribui para criar ou reforçar estereótipos desses alunos como alienados, rebeldes e sem compromisso com os estudos. Esses estereótipos instituídos, muitas vezes, contribuem para o fracasso do aluno no processo educacional. Além desses aspectos, Carrano $(2007$, p.7) destaca também:

Outra fonte de tensão entre jovens e educadores encontra-se na entrada das culturas juvenis nos espaços escolares. As expressões juvenis estão voltadas para a coesão de seus grupos de referência - aquilo que chamamos por vezes de referências tribais - códigos, emblemas, valores e representações que dão sentido ao pertencimento a grupos. A relação dos jovens com seus grupos de referência provoca choques com os valores das instituições (especialmente a escola e a família). O mercado tem conseguido ser muito mais hábil em perceber estes sinais para dialogar lucrativamente com as culturas juvenis e gerar espaços de pertencimento.

Em acordo com o autor, precisamos perceber que, na relação professor-aluno, é necessário o diálogo sobre temáticas que possam despertar e motivar o seu interesse. Pois, infelizmente, o jovem não tem visto na escola um lugar de pertencimento, mas, um espaço de conflitos entre as culturas, no qual seus valores e particularidades, na maioria das vezes, não são reconhecidos pelos docentes e tampouco pelos funcionários. Dessa maneira, é substancial fazer com que o cotidiano escolar seja prazeroso, no sentido de dar voz aos alunos, para que se sintam percebidos nesses espaços. A propósito, Freire (2016, p.95) argumenta que "[...] quanto mais solidariedade exista entre o educador e educandos no 'trato' deste espaço, tanto mais possibilidades de aprendizagem democrática se abrem na escola". Para tanto, é fundamental ser um educador não apenas para transmitir conteúdos sistematizados, é preciso saber ensinar aos alunos reconhecer seus direitos e deveres como cidadão. 
Assim, a Secretaria de Educação do Estado da Bahia (SEC/BA) elaborou uma proposta pedagógica denominada Programa Tempo Juvenil ${ }^{6}$, com características semelhantes ao tempo formativo da EJA, a qual visa atender jovens entre 15 e 17 anos com distorção idade/série no ensino fundamental. O aluno ao finalizar essa etapa, estará apto a ingressar no ensino médio, seja no ensino regular diurno/noturno, ou na EJA.

Apesar da existência dessa proposta, esta não é uma condição que impeça os jovens menores de 18 anos serem matriculados na EJA do noturno, pois, quando o jovem possui a necessidade de trabalhar, é possível que ele seja inserido no ensino noturno. Esta mudança é realizada por intermédio de uma autorização escrita, assinada pelos responsáveis, informando ao órgão competente, no caso a Secretaria de Educação, sobre as razões pelas quais o estudante precisa dar continuidade aos estudos à noite. Esta é a razão de muitas vezes encontrarmos na sala de aula da EJA, noturno, alunos menores de 18 anos, constituindo-se um ambiente heterogêneo, quando o assunto é a faixa etária desses discentes.

A proposta Tempo Juvenil não consta no documento da Política da EJA, pois foi instituída no ano de 2013 nas escolas com o objetivo de trabalhar temas geradores, do mesmo modo como é determinado para a EJA. O documento da EJA no estado da Bahia (Brasil) aponta ainda sete compromissos com a finalidade de afirmar o direito e acesso à Educação dos Jovens e Adultos, evidenciando:

1. Inserir a EJA no campo de Direitos Coletivos e de Responsabilidade Pública; 2. Assumir a Política de EJA na atual política do Estado, definida no documento Princípios e Eixos de Educação na Bahia; 3. Assegurar a EJA como oferta de educação pública de direitos para jovens e adultos, com características e modalidades adequadas às suas experiências de vida e de trabalho, garantindo as condições de acesso e permanência na EJA, como direito humano pleno que se efetiva ao longo da vida; 4. Fazer a opção político-pedagógica pela Educação Popular, pela Teoria Psicogenética que explica a construção do conhecimento, e pela Teoria Progressista/ Freireana (à luz da visão do ser humano integral e inacabado); 5. Adotar os seguintes Eixos Temáticos: a identidade, o trabalho, a cultura, a diversidade, a cidadania, as diversas redes de mobilização social e a Pedagogia da Libertação; 6 . Garantir o princípio básico de que todo ser humano

\footnotetext{
${ }^{6}$ Este programa foi criado em caráter preliminar no ano de 2013 pela Secretaria de Educação da Bahia. Ele orienta a prática pedagógica e o currículo para o público jovem com distorção idade/série, no sentido de garantir estratégias eficazes para potencializar as expectativas desses adolescentes. Assim, o currículo é organizado em Eixos Temáticos e Temas Geradores próximos do contexto dos alunos. O Tempo Juvenil é organizado em etapas que correspondem ao ensino fundamental do 1ㅇ ao 9ㅇa ano (BAHIA, 2013).
}

Periódico Horizontes - USF - Itatiba, SP - Brasil - e020041 
tem direito à formação na especificidade de seu tempo humano, assegurandoIhe outros direitos que favoreçam a permanência e a continuidade dos estudos; 7. Respeitar e implementar os princípios pedagógicos tão caros à Educação Popular e, consequentemente, à EJA, quais sejam: o fazer junto, a dialogicidade e o reconhecimento dos saberes dos educandos (BAHIA, 2009, p.14).

Vale considerar que, para assegurar esses compromissos estabelecidos pelo documento, é importante a parceria do professor nesse processo, no sentido de desenvolver em sala de aula um ensino que se diferencie do ensino regular, especialmente no que diz respeito a abordagem dos conteúdos. É preciso abandonar o currículo engessado e, muitas vezes, fragmentado, reconhecendo as especificidades da EJA. No entanto, é importante lembrar que o professor precisa de apoio na escola, horários para o planejamento e, sobretudo, reconhecimento profissional.

\section{Orientações metodológicas e organização do currículo para a EJA}

De acordo com a concepção desenhada para a EJA no texto da Política do estado da Bahia (Brasil), as orientações metodológicas para a elaboração curricular versam sobre o reconhecimento dos saberes construídos, o respeito às especificidades, o diálogo e o trabalho coletivo. Tais orientações (BAHIA, 2009) têm como norteadores da prática pedagógica 13 princípios, dentre os quais destacamos alguns por considerar mais relevantes para o processo de aprendizagem:

(a) Reconhecimento e valorização do amplo repertório de vida dos sujeitos da EJA: saberes, culturas, valores, memórias, identidades, como ponto de partida e elemento estruturador de todo o estudo das áreas de conhecimento; (b) Construção coletiva do currículo que contemple a diversidade sexual, cultural, de gênero, de raça/etnia, de crenças, valores e vivências específicas aos sujeitos da EJA; (c) Metodologia adequada às condições de vida dos jovens e adultos e relacionada ao mundo do trabalho, devendo, portanto, possibilitar a problematização da realidade existencial e favorecer o aprender a conhecer e o fazer fazendo; (d) Material didático adequado a este tempo de educação, objetivando o desenvolvimento da pluralidade de dimensões da formação humana. Deve-se explorar pedagogicamente as potencialidades formadoras do trabalho como princípio educativo; (e) Acompanhamento do percurso formativo, com base no princípio da dialogicidade no processo de construção e reorientação do trabalho educativo (BAHIA, 2009, p.15-16). 
Nota-se que há uma preocupação da Política em dar um enfoque no reconhecimento e na valorização dos sujeitos quanto aos saberes, crenças, memórias e ao fato de que o processo de aprendizagem precisa ser fundamentado no diálogo. Isso demanda, segundo Freire (2016, p.132), o "[...] respeito às diferenças entre mim e eles ou elas, na coerência entre o que faço e o que digo, que me encontro com eles ou com elas. É na minha disponibilidade à realidade que construo a minha segurança $[. . .]^{\prime \prime}$. Cabe destacar, ainda, que o desenvolvimento do currículo no contexto da EJA implica a adoção de novas metodologias de ensino fundamentadas no diálogo, considerando a realidade sociocultural dos alunos.

Além disso, o documento destaca que o currículo deve ser construído de forma coletiva para atender à diversidade encontrada na EJA. Nesse contexto, Capucho $(2012$, p.82) argumenta que:

\begin{abstract}
Em um cenário propenso às inovações, apresentou-se crescente a crítica aos modelos de currículo organizados em disciplinas dispostas de modo fragmentado e sem correlação, sendo apontadas como urgente a necessidade de repensar o ensino tradicional e o modelo clássico da escola por meio de propostas mais dinâmicas, mais próximas à realidade dos(as) estudantes, envolvendo-os(as) efetivamente no processo educativo, formando para a vida.
\end{abstract}

Em outras palavras, é preciso criar currículos flexíveis, menos fragmentados e mais próximos da realidade, reconhecendo os processos de aprendizagens formais e informais. Nessa perspectiva, conforme defende Sacristán (2000, p.30), “[...] o currículo é um dos conceitos mais potentes, estrategicamente falando, para analisar como a prática se sustenta e se expressa de uma forma peculiar dentro de um contexto escolar", e o professor é um dos agentes ativos nesse processo. Ainda de acordo com Sacristán (2000, p.164) “[...] o currículo molda os docentes, mas é traduzido na prática por eles mesmos - a influência é recíproca". De fato, existe uma concepção do educador como mediador do currículo que se materializa na prática pedagógica por meio de uma rede de saberes e fazeres cotidianos.

Com essas constatações, a política, ao evidenciar a construção coletiva da proposta curricular, orienta que essa construção deve seguir os Tempos Formativos, os Eixos Temáticos e os Temas Geradores. A partir disso, as áreas do conhecimento deverão se organizar com o objetivo de trabalhar de forma contextualizada e interdisciplinar, visando desenvolver a 
aprendizagem dos educandos. No entanto, apesar do documento destacar a abordagem dos conteúdos por meio de Eixos Temáticos e Temas Geradores, não aponta caminhos para o professor fazer as articulações necessárias entre eixos, temas e os conteúdos de cada componente curricular. A ausência de orientação mais direcionada no documento contribui para que os professores apresentem dificuldades em tornar esses eixos e temas elementos de aproximação com o universo de conhecimento dos alunos, o que pode dificultar a implementação da proposta em suas aulas.

Cabe considerar também que os professores da EJA não possuem condições de trabalho apropriadas para desenvolver de forma coletiva um currículo que atenda os Tempos Formativos, Eixos e Temas Geradores. Muitas vezes trabalham com turmas numerosas, alunos com ritmos de aprendizagem diferentes, o que exige do professor uma maior afinidade e formação para atender as demandas que o público da EJA exige. Assim, ressaltamos a necessidade de proporcionar aos professores melhores condições de formação continuada e de trabalho que permitam ter carga horária compatível com as demandas, no sentido de criar espaços para que estes possam elaborar coletivamente currículos adaptáveis ao contexto da EJA.

Ao consideramos os aspectos sociais da EJA para a construção de um novo currículo, reportamo-nos a Apple (2006, p.103) quando adverte que esse também pode ser um "mecanismo de controle social". Aponta ele que o currículo não é neutro nem aleatório, por isso, é preciso refletir sobre o porquê de determinado conhecimento fazer parte do programa da escola e representar os interesses de alguns grupos. É necessário entendermos quais são seus interesses sociais e econômicos, haja vista que estes guiaram a seleção e organização do currículo. Por todas essas razões, a sua construção precisa ser pensada e organizada com propostas que atendam às necessidades formativas dos jovens e adultos. Sobretudo, ele deve ser flexível e aberto a mudanças, pois o currículo implantado nas escolas é responsável pelo sucesso ou fracasso dos educandos.

Nesse sentido, o currículo da EJA deve abranger as diferentes concepções da formação humana, como os valores, o conhecimento social, político e cultural. Para tanto, no trabalho com a EJA, o currículo deve ser orientado com base na diversidade de alunos, considerando suas culturas e seus saberes.

A proposta curricular da rede estadual está organizada em Tempos Formativos que foram 
originados da discussão de temas abordados em conferências, como podemos observar a seguir.

10 Tempo: Aprender a Ser, contendo 03 Eixos Temáticos, com 01 ano de duração cada um (Identidade e Cultura; Cidadania e Trabalho; Saúde e Meio Ambiente); 2ㅇ Tempo: Aprender a Conviver, contendo 02 Eixos Temáticos, com 01 ano de duração cada um (Trabalho e Sociedade; Meio Ambiente e Movimentos Sociais); 3o Tempo: Aprender a Fazer, contendo 02 Eixos Temáticos, com 01 ano de duração cada um (Globalização, Cultura e Conhecimento; Economia Solidária e Empreendedorismo) (BAHIA, 2009, p.20).

Conforme a orientação do documento, os conhecimentos específicos das áreas devem tomar como referência os conteúdos indicados para a EJA apresentados pelo Ministério da Educação. Essa orientação mostra que, apesar de a política ter a intenção de trabalhar com temas, ainda não conseguiu desvincular-se totalmente dos conteúdos adotados no currículo do ensino regular. A organização do currículo deve contemplar o processo de formação, os saberes, a diversidade de vivências e o desenvolvimento pleno do ser humano. Cabe considerar que atualmente vários problemas afetam a EJA, entre eles, o conflito em torno do currículo, no qual o professor no exercício da prática pedagógica não consegue distanciar-se dos conteúdos estabelecidos para o ensino regular.

Nessa perspectiva, para cumprir os compromissos que o documento Política de EJA do estado da Bahia aponta, é urgente a criação de espaços que possibilitem diálogos permanentes entre os envolvidos, tendo em vista proporcionar momentos entre as áreas do conhecimento que fortaleçam e criem novas estratégias educativas com a finalidade de ampliar o campo de formação dos alunos. O currículo assume uma finalidade muito importante na sociedade e em particular no contexto da EJA, no qual os desafios emergem constantemente e o desejo de promover uma educação humanizadora e emancipadora constitui um desafio ímpar, particularmente quando o olhar se volta para a cultura de desvalorização da educação e, sobretudo, a violência contra o professor que tem marcado os últimos tempos.

\section{Considerações finais}

Neste artigo buscamos discutir alguns aspectos relacionados às políticas públicas educacionais, demostrando o papel do governo e das agências multilaterais engajadas no 
ordenamento e padronização da educação com vistas a ascensão quantitativa dos resultados pelos quais são submetidas as escolas. Além disso, as influências dessas agências junto aos autores das políticas sempre deixam as suas marcas nas arenas de disputas, e essa é uma das razões que explica a educação ainda não encontrar um ponto de equilíbrio entre os descompassos no âmbito estrutural e pedagógico que acometem em particular a Educação de Jovens e Adultos.

Com relação à política de EJA do estado da Bahia (Brasil), analisamos questões emblemáticas sobre os desafios para a modalidade, orientações metodológicas e organização curricular. Ao analisarmos esse conjunto de demandas é importante considerar que as políticas são textos, nos quais as lutas se travam e alguns nem sempre consegue deixar suas marcas no processo de constituição destas políticas. No entanto, apesar das iniciativas elencadas na política curricular de EJA do estado da Bahia, resultados de reuniões dos diversos segmentos da sociedade, ainda assim, somente algumas vozes foram ouvidas e legitimadas.

Nesse contexto, ressaltamos que a EJA deve ser compreendida como uma modalidade de formação humana num processo contínuo e emancipador, exigindo do professor conhecimentos epistemológicos necessários para consolidar uma percepção de como os jovens e adultos constroem seus espaços de atuação na sociedade. Essa nova forma de pensar e construir a EJA se faz mais urgente no momento atual, pois, como foi sinalizado no texto da política, o público da EJA vem se modificando. Uma dessas modificações corresponde à presença do público jovem, adolescente ocupando as salas da EJA no noturno. Os resultados dessa análise destacam, conforme apontado no documento, o descontentamento do professor com relação a esse aspecto, o que nos faz concluir que, a forma como estes lidam com a situação pode contribuir para a formação de uma visão negativa e, sobretudo, estereotipada desses adolescentes.

Contudo, a Secretaria Estadual de Educação, ao detectar esse problema, criou o programa Tempo Juvenil, uma proposta de formação para esse público, mas, infelizmente, em algumas escolas do município de Vitória da Conquista, campo desse estudo, o referido programa foi extinto. Acreditamos que o motivo não é a ausência de alunos para essa modalidade, mas a falta de continuidade das políticas educacionais, muitas vezes, marcadas por avanços e retrocessos e conforme os interesses dos envolvidos.

Tendo em vista os aspectos analisados, a organização curricular da EJA no estado da Bahia (Brasil) prima por uma construção coletiva, tomando como bases os Eixos Temáticos e Temas 
Geradores. Porém, não é dado ao professor espaço para torná-lo realidade dentro dos parâmetros exigidos. As áreas do conhecimento continuam separadas em dias de planejamento e, normalmente, nas escolas não há um momento coletivo, o que causa uma enorme lacuna na implementação e nos modos de compreender o próprio documento. Isso mostra uma certa fragilidade na gestão das políticas que chagam às escolas, reforçando desigualdades com reflexos diretamente na formação dos alunos.

Assim, elucidamos que as políticas de educação são textos que resultam de múltiplas influências e, ao serem implementadas na escola, revelam um campo de tensões nas vozes dos professores. Os resultados demonstram que a Política de EJA do estado da Bahia está fundamentada em uma perspectiva crítica de educação, a qual reconhece as competências, a solidariedade, o respeito aos direitos dos jovens e adultos e o pluralismo de ideais. Contudo, a concepção de um novo currículo apresentada pelo documento demanda mudança de postura e, principalmente, ações que vislumbrem a valorização do trabalho docente.

\section{Referências}

APPLE, M. W. Ideologia e currículo. 3.ed. Porto Alegre: Artmed, 2006.

BAHIA. Secretaria da Educação. Coordenação de Educação de Jovens e Adultos. Política de EJA da rede estadual: aprendizagem ao longo da vida. Salvador: Secretaria da Educação, 2009. Disponível em: http://www.sec.ba.gov.br/jp2011/documentos/Proposta_da_EJA.pdf Acesso em: 26 jul. 2017.

BAHIA. Secretaria de Educação. Proposta pedagógica do Tempo Juvenil / ensino fundamental para estudantes de 15 a 17 anos. Salvador, 2013. Disponível em: http://www.sec.ba.gov.br/jp2011/document/Proposta_da_EJA.pdf Acesso em: 10 jan.2020.

BALL, S. Education reform: a critical and post-structural approach. Buckingham: Open University Press, 1994.

BARDIN, L. Análise de conteúdo. São Paulo: Ed. 70, 2016.

BRASIL. Estatuto da Criança e do Adolescente. Lei no 8.069. Brasília, 13 de julho de 1990.

Disponível em: http://www.planalto.gov.br/ccivil_03/leis//8069.htm Acesso em: 25 nov. 2018.

BRASIL. Conselho Nacional de Educação. Parecer CNE/CEB no 6/2010. Diretrizes Curriculares Nacionais para a Educação de Jovens e Adultos. Brasília: MEC, junho 2010. Disponível em: 
http://portal.mec.gov.br/index.php?option=com_content\&view=article\&id=15074\&ltemid=86 6. Acesso em: 19 nov. 2018.

CAPUCHO, V. Educação de Jovens e Adultos: prática pedagógica e fortalecimento da cidadania. São Paulo: Cortez, 2012.

CARRANO, P. Educação de jovens e adultos e juventude: o desafio de compreender os sentidos da presença dos jovens na escola da "segunda chance". REVEJ@: Revista de Educação de Jovens e Adultos. 2007. Disponível em:

http://www.reveja.com.br/revista/0/artigos/REVEJ@_0_PauloCarrano.pdf Acesso em: 19 nov.2018.

FREIRE, P. Política e educação. 7.ed. São Paulo: Cortez, 2003.

FREIRE, P. Pedagogia da autonomia: saberes necessários à prática docente. 54.ed. Rio de Janeiro: Paz e Terra, 2016.

GADOTTI, M. Educação de Adultos como direito humano. 4.ed. São Paulo: Editora e Livraria Paulo Freire, 2009.

LIBÂNEO, J. C. Políticas educacionais no Brasil: desfiguramento da escola e do conhecimento escolar. Cadernos de Pesquisa, São Paulo, v.46, n.159, p.38-82, jan./mar. 2016. Disponível em: http://publicacoes.fcc.org.br/ojs/index.php/cp/article/view/3572. Acesso em: 21 nov.2018.

LOPES, A. C.; MACEDO, E. Teorias de currículo. São Paulo: Cortez, 2011a.

LOPES, A. C.; MACEDO, E. Contribuições de Stephen Ball para o estudo de políticas de currículo. BALL, S.; MAINARDES, J. (Orgs.). Políticas educacionais: questões e dilemas. São Paulo: Cortez, 2011b.

MAINARDES, J. Abordagem do ciclo de políticas: uma contribuição para a análise de políticas educacionais. Educação e Sociedade, Campinas, v.27, n.94, p.47-69, jan./abr. 2006. Disponível em: http://www.scielo.br/pdf/es/v27n94/a03v27n94.pdf Acesso em: 17 set. 2018.

MINAYO, M. C. O desafio do conhecimento: pesquisa qualitativa em saúde. 14.ed. São Paulo: Hucitec, 2014.

SACRISTÁN, J. G. O currículo: uma reflexão sobre a prática. 3.ed. Porto Alegre; Artmed, 2000.

SAVIANI, D. Sistema Nacional de Educação e Plano Nacional de Educação: significado, controvérsias e perspectivas. Campinas: Autores Associados, 2014.

Recebido em fevereiro 2020.

Aprovado junho 2020. 